\title{
Description of Lutzomyia (Lutzomyia) falquetoi sp. nov. (Diptera: Psychodidae, Phlebotominae) a new species from the state of Espírito Santo, Brazil
}

\author{
Israel de Souza Pinto/ ${ }^{+}$, Claudiney Biral dos Santos* \\ Unidade de Medicina Tropical, Universidade Federal do Espírito Santo, Av. Marechal Campos 1468, 29040-090 Vitória, ES, Brasil \\ *Núcleo de Entomologia da Secretaria de Saúde do Estado do Espírito Santo,Vitória, ES, Brasil
}

Lutzomyia (Lutzomyia) falquetoi, sp. nov. (Diptera: Psychodidae, Phlebotominae) is described from the state of Espirito Santo, Brazil. This new species belongs to the series longipalpis and is easily distinguished from the other members of this taxon by the presence of five well-developed spines and a pre-apical spiniform bristle on the gonostyle as well as nine bristles on the basal tuft of the gonocoxite.

Key words: Lutzomyia (Lutzomyia) falquetoi sp. nov. - Phlebotominae - taxonomy - Espírito Santo - Brazil

The genus Lutzomyia França, 1924 includes the highest number of species in the New World phlebotomine fauna and is subdivided into many subgenera or groups of species, as well as several isolated species (Barretto 1962, Theodor 1965, Lewis et al. 1977, Martins et al. 1978, Young \& Duncan 1994). Galati $(1995,2003)$ divided Lutzomyia among the three subtribes: Sergentomyiina Artemiev, 1991, Psychodopygina Galati, 1995 and Lutzomyiina Abonnenc \& Leger, 1976. The genus can also be divided into the subgenera $\mathrm{Hel}$ cocyrtomyia Barretto, 1962, Castromyia Mangabeira, 1942, Tricholateralis Galati, 1995, and Lutzomyia s.str. The L. (Lutzomyia) species recognized by Young and Duncan (1994) were split into the subgenera Lutzomyia, s.str., Castromyia, and Tricholateralis by Galati (1995, 2003) who also removed the species $L$. cipoensis and $L$. gasparviannai and placed them in another subtribe. Martins et al. (1978) included the same species as Galati (2003) in the subgenus Lutzomyia but divided it into two series: longipalpis and cavernicola.

According to Martins et al. (1978) and Galati (1995, 2003), males of the subgenus Lutzomyia have the 5th palpomere slightly longer than the sum of the 4 th +3 rd segments, the gonocoxite with a basal tuft formed by a variable number of bristles and 2-5 strong spines on the dorsal margin of the paramere, which generally ends in a hook. In males of the series longipalpis the gonostyle has a well-developed apical spine with a subterminal bristle present or absent. There may be $2-6$ bristles with a variety of shapes (spiniform, semifoliaceous, folia-

\footnotetext{
+Corresponding author: ispinto@cbm.ufes.br

Received 5 October 2006

Accepted 5 January 2007
}

ceous or fan-like) at the base of the gonocoxite. The paramere has two or more bristles that generally have curved tips, but which may also be straight or fan-like, implanted on the median region of the dorsal margin; the lateral lobe has a rounded, unarmed apex. The series cavernicola differs from longipalpis by the presence of two well-developed apical spines on the gonostyle (Martins et al. 1978).

Two males of a new phlebotomine species, closely related to those of the series longipalpis, were captured during a survey of the sand fly fauna of Espírito Santo, Brazil. The new species is described here.

\section{MATERIALS AND METHODS}

The specimen was described based on the terminology and morphological characters proposed by Galati (2003). The insect was cleared and mounted on a slide under a coverslip (Barretto \& Coutinho 1940). The characters of the insect were measured (in $\mathrm{mm}$ ) using an Olympus ${ }^{\circledR} \mathrm{CH} 30$ ocular micrometer, calibrated with a graduated reference slide and drawn under an Olympus® camera lucida.

\section{DESCRIPTION \\ Lutzomyia (Lutzomyia) falquetoi sp. nov.} (Figs 1 A-C, 2 D-F)

Male - Holotype. Total length 3764. General colour light brown, with notum slightly darker than pleura, coxae and legs.

Head - Length 0.412 , not including clypeus 0.105 long. Ratio of head/clypeus lengths 3.060. Head width 0.510 . Distance between eyes 0.150. Labial fork present. Length of labro-epipharynx 0.472 . Lengths of palpomeres: pI 0.045; pII 0.195; pIII 0.217; pIV 0.172 and $\mathrm{pV}$ 0.495. Palpal formula 1.4.2.3.5. Segment $\mathrm{pV}$ slightly longer than all the others, equivalent to the sum of pII + pIV and little more than pIII + pIV. Newstead's spines implanted sparsely on pII and pIII. Antennal ascoids on AIII - AXV. Antennal formula AIII - AXV 2, AXVI 0. Internal ascoid of AIV implanted at a distance slightly more proximal than external one. Pre-apical papilla present on AIII, AIV and AV. Apical papilla on segments AXIII, 

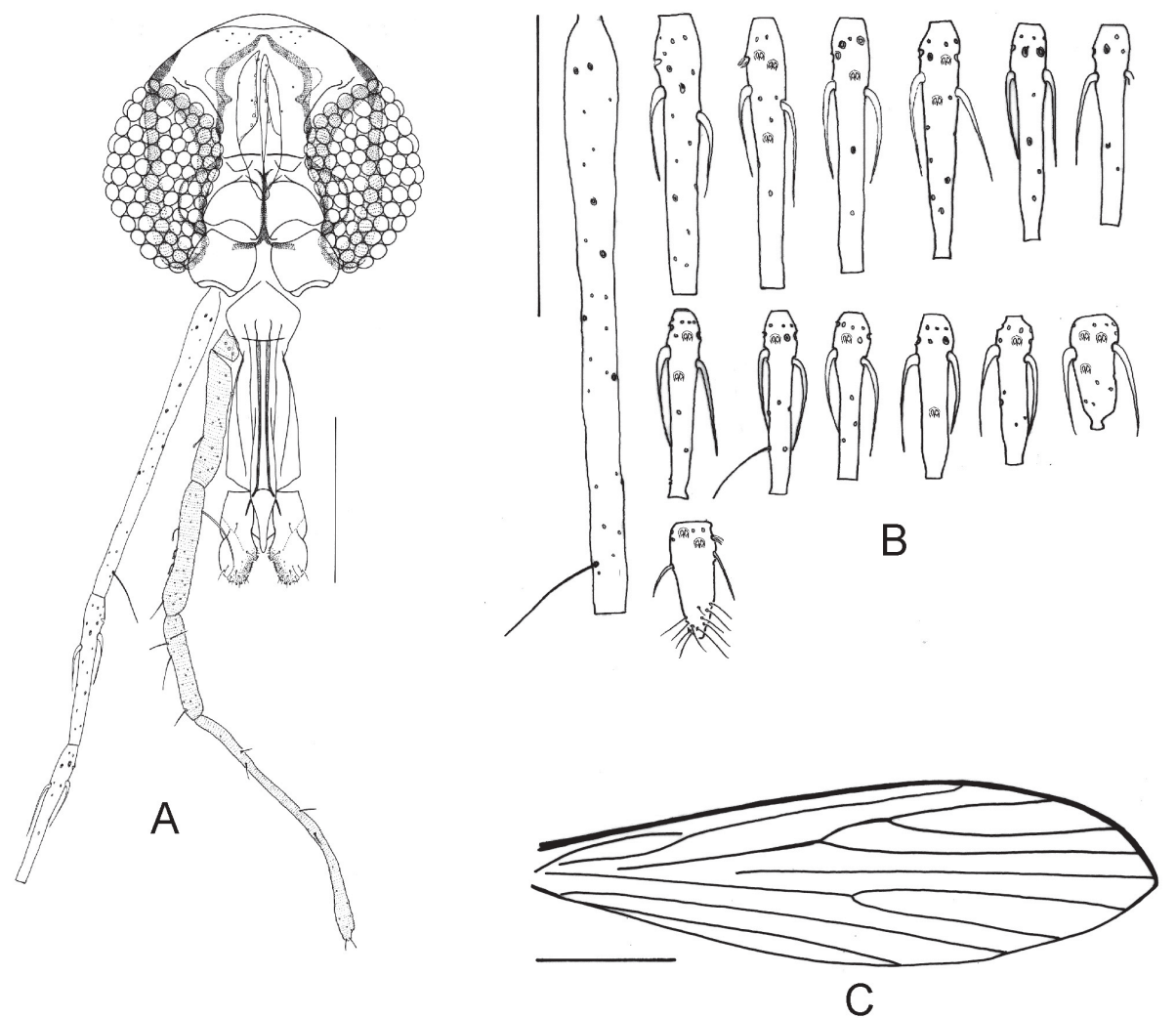

Fig. 1: Lutzomyia (Lutzomyia) falquetoi sp. nov. (male). A: head. Bar: 0.2 mm; B: antenna segments: AIII-AXVI. Bar: 0.2 mm; C: wing. Bar: 0.5 mm.
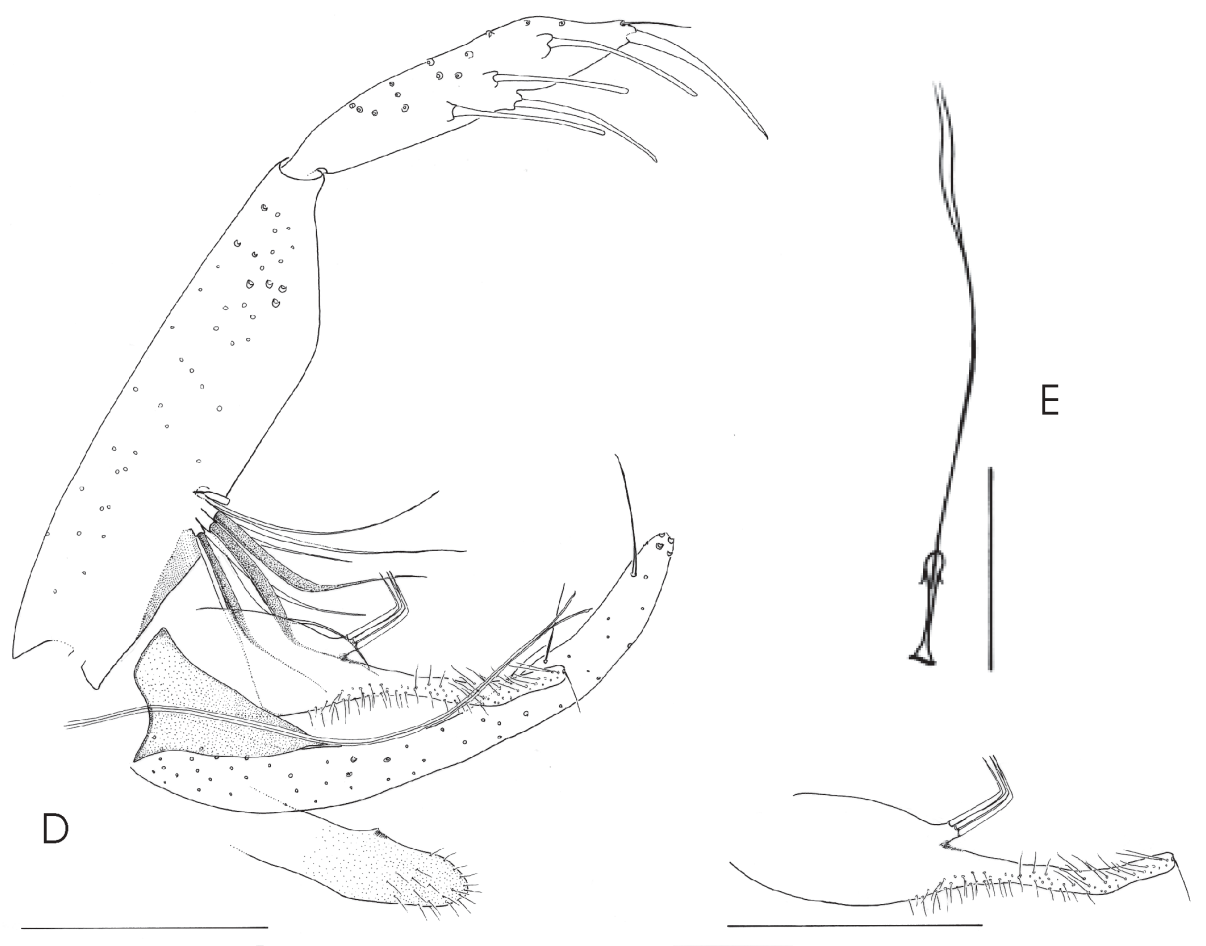

$\mathrm{F}$

Fig. 2: Lutzomyia (Lutzomyia) falquetoi sp. nov. (male). D: genitalia. Bar: $0.2 \mathrm{~mm}$; E: genital pumps and filament (paratipe). Bar: $0.36 \mathrm{~mm}$; F: paramere. Bar: $0.2 \mathrm{~mm}$ 
AXIV, AXV, and AXVI. Lengths of antennal segments: AIII - 0.630: AIV - 0.292; AV - 0.277; AVI - 0.262; AVII 0.247; AVIII - 0.232; AIX - 0.217; AX - 0.195; AXI 0.180 ; AXII - 0.172; AXIII - 0.157; AXIV - 0.142; AXV 0.127 , and AXVI - 0.120.

Cervix with ventral sensillae.

Thorax - Notum slightly darker than pleura, coxae and legs. Length of thorax 0.937 . Length of coxae: anterior 0.375 ; median 0.547 and posterior 0.502 . Length of the femora: anterior 1.485 and median 1.395. Length of the tibiae: anterior 2.198 and median 2.295. Length of tarsi anterior: TI 1.215; TII 0.525; TIII 0.315; TIV 0.240; and TV 0.150. Length of the median tarsi: TI 1.350; TII 0.525; TIII 0.315; TIV 0.240; and TV 0.150. Posterior legs lost on specimen examined. Wing: length 3.487, width 0.900 . Ratio length/width 3.875 . Principal wing vein lengths: $\alpha$ (R2) $0.787 ; \beta(\mathrm{R} 2+3) 0.712 ; \gamma(\mathrm{R} 2+3$ + 4) $0.300 ; \delta$ (part of R1 that extends beyond junction of R2 + R3) 0.412. Three proepimeral and eight upper anepisternal bristles present. Bristles on metepisternum and anterior katepisternum absent. Abdomen: total length 2.400, not including the genitalia. Papillae present on tergites 4, 5, and 6. Genitalia: gonocoxite length 0.675 ; width 0.172 ; ratio length/width 1.739 ; basal tuft of nine long bristles implanted in tubercle on internal surface, three being foliaceous and the remainder filiform. Gonostyle length 0.450 ; width 0.075 ; ratio length/width 6.0 ; bearing strong spines and subterminal seta. One spine terminal, three positioned in distal half and one in the proximal half of gonostyle. Spiniform pre-apical bristle present. Paramere length $0.600 ; 0.105$ wide at base, narrowing rapidly towards middle, but dilating slightly at apex. Median of the dorsal margin with welldeveloped tubercle, 0.030 long and 0.015 wide, on which three long spines are inserted, each 0.300 long, curving abruptly just distally of median to form a right angle. Small spines inserted from median to apex of the paramere. Lateral lobe length 0.862 and width 0.060 , extending slightly beyond the paramere, with uniform thickness. Small, simple bristles present. Cercus 0.450 long and 0.097 wide. Aedeagus triangular 0.300 long and 0.075 wide at base. Genital pump thin, 0.262 long, with pavilion little developed. Genital filaments thin and 1.050 long, with thin tips.

Type material - Male holotype and paratype. Brazil, Espírito Santo, municipality of Mucurici, locality of Córrego Itauninhas (18 04,336’ S 40 32,623' W; 217 $\mathrm{m}$ a.s.1.). Col. Pinto I. S. \& Santos C. B., 24.IX.2005, using Castro aspirator. Both specimens were deposited in the collection of the International Reference Centre of the Centro de Pesquisas René Rachou-Fiocruz, Belo Horizonte, Brazil. The holotype and paratype numbers are 112.A.1 and 112.A.2, respectively.

Etymology - The name L. falquetoi is given in homage to Prof. Aloísio Falqueto, in recognition of his significant contribution to the study of phlebotomines and leishmaniases in Espírito Santo.

\section{TAXONOMIC DISCUSSION}

Based on the characters described above, particularly those of the genitalia, L. falquetoi sp. nov. should undoubtedly be included in the subgenus Lutzomyia (Martins et al. 1978, Young \& Duncan 1994, Galati et al. 2003), while the single well-developed apical spine on the gonostyle allows it to be placed within the series longipalpis (Martins et al. 1978). It can be distinguished from all other species in this series, i.e., L. alencari Martins, Souza \& Falcão, 1962, L. bifoliata, OsornoMesa, Morales-Alarcon, Osorno \& Hoyos, 1970, L. cruzi (Mangabeira, 1938), L. dispar Martins \& Silva, 1963, L. gaminarai (Cordero, Vogelsang \& Cossio, 1928), L. ischnacantha Martins, Souza \& Falcão, L. ischyracantha Martins, Falcão \& Silva, 1962, L. lichyi (Floch \& Abonnenc, 1950), L. longipalpis (Lutz \& Neiva, 1912) and L. souzalopesi Martins, Silva \& Falcão, 1970 by the presence of a tuft formed from nine long bristles implanted on a tubercle at the base of the gonocoxite, three being foliaceous and the others filiform, as well as the additional spine implanted between proximal and distal outer spines in the gonostyle. The paramere shape of the new species is also distinctive.

\section{ACKNOWLEDGEMENTS}

To Eunice Aparecida Bianchi Galati, Alda Lima Falcão, and José Dilermando Andrade Filho for reviewing the text and making suggestions; to Bruce Alexander for translating the manuscript; and Ricardo Kawada for drawing the type material.

\section{REFERENCES}

Barretto MP 1962. Novos subgêneros de Lutzomyia França, 1924 (Diptera, Psychodidae, subfamília Phlebotominae). Rev Inst Med Trop São Paulo 4: 91-110.

Barretto MP, Coutinho JO 1940. Processos de captura, dissecação e montagem de flebótomos. An Fac Med Univ São Paulo 16: 173-187.

Galati EAB 1995. Phylogenetic systematics of Phlebotominae (Diptera, Psychodidae) with emphasis on American groups. Bol Dir Malariol San Amb 35 (Supl. 1): 133-142.

Galati EAB 2003. Morfologia e Taxonomia. 2.2 - Morfologia, terminologia de adultos e identificação dos táxons da América. In EF Rangel, R Lainson (eds), Flebotomineos do Brazil, Fiocruz, Rio de Janeiro, p. 53-175.

Lewis DJ, Young DG, Fairchild GB, Minter DM. 1977. Proposals for a stable classification of the phlebotomine sandflies (Diptera: Psychodidae). Syst Entomol 2: 319-332.

Martins AV, Williams P, Falcão AL 1978. American Sand Flies (Diptera: Psychodidae: Phlebotominae), Acad Bras Ciênc, Rio de Janeiro, $195 \mathrm{pp}$.

Theodor O 1965. On the classification of American Phlebotominae. J Med Entomol 2: 171-197.

Young DG, Duncan MA 1994. Guide to the Identification and Geographic Distribution of Lutzomyia Sand Flies in Mexico, the West Indies, Central and South America (Diptera: Psychodidae), Mem Am Entomol Inst 54, Associated Publishers, 881 pp. 